\title{
Effects of Prolactin and Somatotropin on Growth and Metamorphosis of Amphibians
}

\author{
B. E. FRYE \\ Department of Zoology, University of Michigan, Ann Arbor, Michigan
}

AND

PATRICIA S. BROWN

Department of Biology, Siena College, Loudonville, New York

AND

B. W. SNYDER

Department of Population Dynamics, Johns Hopkins University, School of Hygiene and Public Health, Baltimore, Maryland

\begin{abstract}
Mammalian prolactin stimulates growth and inhibits metamorphosis of larvae of several species of amphibians. Mammalian somatotropin has little or no effect upon larval growth or metamorphosis unless used in high concentrations. The evidence behind these statements and some of the implications are critically evaluated. Growth of postmetamorphic amphibians is stimulated by somatotropin but not by prolactin. The possible biological signifieance of this apparent transition from prolactin to somatotropin regulation of growth in the pre- and postmetamorphic stages of development is discussed in terms of possible mechanisms involved in the transition, and in terms of the adaptive significance of the change.
\end{abstract}

The best current model of hormonal regulation of amphibian development proposes a double system of control consisting of thyroxine, which stimulates metamorphosis and thus brings larval growth to a halt, and prolactin, which has the combined effects of stimulating larval growth and inhibiting metamorphosis (Etkin and Gona, 1967; Bern, Nicoll, and Strohman, 1967; Etkin, 1968). The secretion of these two hormones is presumed to follow a reciprocal pattern of rising thyroxine and declining prolactin as metamorphosis progresses, the pattern being determined by developmental changes in the thyrotropin releasing and prolactin inhibiting functions of the hypothalamus. We will review some of the evidence for the role of prolactin in amphibian growth and metamorphosis. Since a major part of the growth of most species of amphibians takes place after metamorphosis, comparison of the endocrine regulation of growth during this phase of the life cycle with the larval phase is of particular interest and will be discussed in the latter part of the paper. Most of the information which will be discussed is based on work with relatively highly purified mammalian hormones. There is fortunately some support for this work from $x$ few studies of the effects of hypophysectomy and implants or homogenates of amphibian pituitary on growth and metamorphosis.

\section{LARVAL GROWTH}

The pituitary gland has been known to play a role in the control of growth of amphibian larvae since thc first quarter of this century when several investigators 
showed that growth is retarded by hypophysectomy and stimulated by implants or extracts of adult amphibian or bovine pituitary glands (cf. Smith, 1920; Allen, 1929; Willier, 1955). These observations have been confirmed in recent years (Etkin and Lehrer, 1960; Enemar and Mecklenburg, 1962; Hanoka, 1967; Olivero et al., 1968). There was no indication in the earlier sludies as to the nature of the growth promoting factor(s), or even whether a specific growth hormone was involved as opposed to growth effects which were secondary to effects of the pituitary upon adrenal and thyroid function. Although we now know that mammalian prolactin is a strong stimulant to tadpole growth (see below), the question of the nature of the growth promoting action of the intrinsic pituitary gland still had not been adequately resolved. The legitimacy of some reservation on this point is underscored by the recent report of Just and Kollros (1968) that immersion of hypophysectomized tadpoles in very dilute solubions of thyroxine $(0.08 \mu \mathrm{g} /$ /iter $)$ is sufficient to restore growth to normal rates.

The first suggestion that prolactin or a prolactin-like hormone might be the specific growth hormone secreted by tadpole pituitaries was made by Ftkin and Lehrer in 1960. They showed that tadpoles bearing ectopic pituitary autografts grow at faster rates and to larger ultimate size than intact animals, and suggested that the ectopic glands were secreting above normal amounts of some growth promoting factor. On the basis of analogy with the mammalian hypothalamo-hypophysial system, in which prolactin secretion is under inhibitory control, they proposed that the tadpole growth factor might be prolactin. The observational basis for this suggestion has been confirmed, both with ectopic grafts (Brown, unpublished), and by hypothalectomy which also leaves the pituitary in a deafferented state (Hanoka, 1966; Remy and Bounhiol, 1966; Guardabassi et al., 1961).

As a result of the work of Etkin and Lehrer, several groups of investigators have studied the effects of prolactin upon the growth of amphibian larvae (Berman et $a l ., 1964$; Remy and Bounhiol, 1965, 1966; Bern et al., 1967; Etkin and Gona, 1967; Gona, 1967; Enemar et al., 1968; Guardabassi et al., 1968; Brown and Frye, 1969a; Medda and Frieden, 1970; Snyder, 1970). This work has shown in larvae of several species of amphibians, including Rana pipiens, R. grilio, R. catesbeiana, R. temporaria, Alyles obstretricans, and Bufo bufo, that mammalian prolactin is a strong stimulator of growth. The growth response to prolactin injections is prompt, usually being noticeable within 3-4 days after treatment is begun, and occurs after reasonably small doses of the hormone. In $R$. pipiens and $R$. catesbeiana doses in the order of $1-50 \mu \mathrm{g} / \mathrm{animal} / \mathrm{day}$ are effeclive in promoting growth, a dose which is roughly equivalent to $0.1-5 \mathrm{mg} / \mathrm{kg}$, or comparable to the effective levels of somatotropin ordinarily used in mammals. On the basis of data published to date it is not possible to characterize the dose response curve satisfactorily. In our hands (Brown and Frye, 1969a) (here is no clear indication of a linear dose-response relationship over the range from $0.5-50 \mu \mathrm{g} /$ animal. Moreover, the minimum effective dose (between $0.5-1 \mu \mathrm{g} /$ animal/day) gives an essentially maximum response. A similar lack of linear dose-response relationship has been reported with respect to the effect of prolactin on urea excretion (Medda and Frieden, 1970). In part this phenomenon may be due to the considerable variability of the response of individual tadpoles. Nonetheless, properly designed dose-response assays using more closely spaced doses of hormone need to be done in order to determine whether the response is graded in some geometric or arithmetic relationship, or whether we are dealing with an all or none response, possibly suggestive of a threshold phenomenon.

The growth response to prolactin has generally been measured in terms of an increase in wet and dry weight, total length, and tail width. In two recent studies prolactin has also been shown to reduce total nitrogen excretion (Medda and Frieden, 1971), an apparently anabolic effect, and 
enhance incorporation of labeled amino acid into protein (Snyder, 1970; Yoshizato and Yasumasu, 1970). In the study by Snyder prolactin significantly enhanced the incorporation of amino acid into protein in two experiments out of three (Table 1 ). In view of the considerable magnitude of the growth response when measured in terms of length or weight increment the modest increment in amino acid incorporation in two experiments, and the lack of a significant effect in the third is rather surprising. This could suggest that the major effect of prolactin is to decrease protein catabolism rather than to stimulate protein synthesis, or it could reflect dilution of the labeled precursor in a large, rapidly turning over amino acid pool with the result that the apparent rate of protein synthesis is lower than the real rate. The effect of prolactin upon protein synthesis occurred without any change in amino acid pool size, and hence is presumably not an effect upon amino acid uptake, but a more direct stimulation of the biosynthetic process. More detailed studies of the biochemical basis of the growth effect of prolactin are badly needed, not only for the sake of establishing the mechanism of action, but also as a possible basis for understanding the interrelationships of prolactin and thyroxine in larval growth and metamorphosis (see below).

Au aspect of the growth promoting action of prolactin which has not been systematically explored is whether the effect is generalized or whether different tissues respond differentially. There are some indications, however. For example, there is a common emphasis in the literature which suggests that the growth of the tail, par- ticularly the fin, is especially sensitive (Yoshizato and Yasumasu, 1970). (This calls to mind the numerous other effects of prolactin upon the integument and its derivatives, ef. Bern and Nicoll, 1968.) Hind-leg growth, on the other hand is not stimulated, and may in fact be inhibited, perhaps due to an antagonism of the action of thyroxine (see below).

The growth promoting effect of prolactin in amphibian larvae may not be entirely specific. Somatotiopin preparations of mammalian origin have been shown to have appreciable growth promoting activity, in some instances as great as or greater than prolactin (Remy and Bounhiol, 1966; Enemar et al., 1968). However, in our hands as well as several other inm vestigators' (Etkin and Gona, 1967; Bern et al., 1967; Brown and Frye, 1969a, Snyder, 1970) the growth stimulating activity of somatotropin is much less than that of prolactin, and can probably be accounted for by the levels of prolactin contaminam tion which most somatotropin preparations have (ef. Brown and Frye, 1969a; Brown and Brown, 1971). Nonetheless, it is posm sible that somatotropin does possess intrinsic growth promoting activity in amphibian larvae. The relative potency of prolactin and somatotropin in inducing growth may vary with the species in which they are tested; with variations in test cirm cumstances such as the time of hormone administration relative to diurnal rhythms (cf. Meier, 1969); or with developmental stage and state of thyroid or other en docrine activity of the test animals. Such factors could readily affect the apparent relative potencies of prolactin and 50 matotropin if they promote growth by

TABLE 1

Incorporation of ${ }^{14} \mathrm{C}$-Amino Acid into Tadpole Tail Muscle aftror Prolactin and Growth Hormonf TrFatment ${ }^{a}$

\begin{tabular}{lccc}
\hline & Expt. 1 & Expt. 3 & Expt. 4 \\
\hline Control & $1287 \pm 150$ & $2139 \pm 178$ & $1767 \pm 135$ \\
Prolactin & $1870 \pm 208^{*}$ & $2147 \pm 148$ & $2245 \pm 154^{b}$ \\
Somatotropin & $1312 \pm 174$ & $1830 \pm 153$ & $1810 \pm 161$ \\
\hline
\end{tabular}

a Taken from Snyder (1970). Values are dpm/mg protein $\times$ weight of tadpole.

${ }^{b}$ Indicates a significant difference with a $p$ of 0.05 . 
different mechanisms. For example, Brown (1968) has shown that thyroidectomy enhances the sensitivity of tadpoles to somatotropin 2-10 times that of intact controls. Under these conditions the effect of somatotropin can no longer be accounted for in terms of prolactin contamination, unless of course thyroidectomy also enhances sensitivity to prolactin. As will be discussed below prolactin acts, in part, by inhibiting metamorphosis, an effect which somatotropin does not have. Since most somatotropin preparations are contaminated with thyrotropin they tend to accelerate metamorphosis. This effect could obliterate any growth promoting action of somatotropin in tadpoles. It is obviously premature to rule out somatotropin as an important growth factor in larval amphibians. In fact, at the present state of knowledge, we cannot deny the possibility that the growth effects of prolactin preparations are due to the combined antimetamorphic effect of prolactin plus a specific anabolic effect of the somatotropin which contaminates these preparations!

\section{METAMORPHOSIS}

We have already alluded to the fact that, in addition to stimulating growth, mammalian prolactin preparations also inhibit metamorphosis (Nicoll et al., 1965; Etkin and Gona, 1967; Gona, 1967, 1968; Bern et al., 1967; Campantico et al., 1968; Derby and Etkin, 1968; Brown and Frye, 1969a; Etkin, Derby and Gona, 1969; Derby, 1970; Gona and Etkin, 1970; Medda and Frieden, 1970). The criteria by which this effect has been shown include prevention of tail reabsorption and other events of metamorphic climax; arrest of the progression of normal developmental stages, and arrest of hind-leg growth, a thyroxine dependent trait which reflects metamorphic progression. Recently prolactin has also been shown to suppress urea excretion by normal or triiodothyronine treated tadpoles (Medda and Frieden, 1970). Since a normal metamorphic rise in urea excretion is induced by thyroid hormones (of. Frieden, 1968) this effect can be interpreted as a repression of the metamorphic transition from ammoniotelism to ureotelism. However, this interpretation must be viewed cautiously since the reduction in urea excretion may reflect an anabolic action of prolactin, causing general nitrogen retention, rather than a specific effect on development of the urea cycle. This reservation seems to be supported by the recent report of Medda and Frieden (1971) that prolactin also reduces ammonia and total nitrogen excretion in tadpoles, and by the observations of Blatt et al. (1969) and Guardabassi et al. (1970) that prolactin does not suppress, and may actually stimulate, carbamyl phosphate synthetase and arginase, key enzymes of the urea cycle. Rough comparison of the data in the two papers of Frieden and Medda suggests that in fact urea excretion is not repressed to a greater degree than ammonia. Data are needed on the precise ratios of ammonia to urea excretion before a good case can be made for inhibition of induction of the urea cycle as opposed to a positive anabolic effect as the basis for this phenomenon.

According to most investigators antimetamorphic effects are possessed only by prolactin, and not by mammalian somatotropin. In fact, somatotropin has been reported several times to accelerate metamorphosis (Bounhiol et al., 1959; Nicoll et al., 1965; Etkin and Gona, 1967; Just and Kollros, 1968; Brown and Frye, 1969a). This may be a consequence of thyrotropin contamination of most somatotropin preparations rather than an effect of somatotropin itself. This view has been tentatively confirmed by the lack of a metamorphosis accelerating effect of a porcine somatotropin preparation which contained very low thyrotropin contamination (Brown, 1968). It is likely that the prolactin preparations which have been used in most experiments also contain significant amounts of thyrotropin, but its activity is apparently obscured by the antimetamorphic effect of prolactin. Prolactin has been shown to overcome the metamorphosis stimulating effect of rather large doses of thyrotropin (Gona, 1967). Therefore it is clear that the action of somatotropin differs from the action of 
prolactin insofar as any effect on metamorphosis is concerned. It may be significant that somatotropin suppresses urea excretion almost as effectively as prolactin (Medda and Frieden), a phenomenon which could suggest that the anabolic actions of preparations of the two hormones are equivalent and that differences relate to their antimetamorphic activities.

Ectopic pituitary grafts also inhibit metamorphosis, whether tested in the whole animal (Etkin et $a l ., 1969$ ) or on pieces of isolated tail fin in vitro (Derby and Etkin, 1968). Moreover, the metamorphosis inhibiting activity of grafts of larval pituitary declines as the donor progresses from prometamorphosis to metamorphic climax, and is undetectable in the pituitary of the postmetamorphic froglet (Derby, 1970). This pattern of change corresponds to the theoretical model for prolactin secretion during metamorphosis mentioned in the introduction. Such information strongly augments the results obtained with mammalian prolactin in indicating that the antimetamurphic effect is a normal physiological function of a larval pituitary hormone, i.e., prolactin or a prolactin-like hormone. A point worthy of note in this connection is that the pituitary implants and extracts used in the early work of Smith and Allen (cf. Allen, 1929) accelerated growth but did not precipitate metamorphosis. Since, as noted above, even relatively highly purified preparations of somatotropin (as well as other pituitary hormones) contain appreciable levels of thyrotropin contamination, these early preparations must surely have contained sufficient amounts of thyrotropin to cause a precipitous onset of metamorphosis. The fact that they did not indicates, in retrospect, that a metamorphosis inhibiting agent, presumably prolactin, must have also been present in those preparations.

Two possible mechanisms for the antimetamorphic action of prolactin have been examined: (1) a central antithyroid effect, the consequence of which is to suppress thyroid hormone secretion; and (2) a peripheral effect which interferes with or counteracts the metamorphic action of thy- roxine on the target tissues. The first possibility has been tested by means of studies of thyroid histology and radioiodine metabolism, with conflicting results by dif.ferent investigators. On the one hand, Gona $(1967,1968)$ finds that prolactin blocks the stimulation of metamorphosis caused by exogenous thyrotropin, but not that caused by exogenous thyroxine. He therefore believes that prolactin blocks at the level of the thyroid the synthesis or secretion of thyroxine, and supports this conclusion by showing that iodine uptake by thyroids of prometamorphic tadpoles is depressed by prolactin. However, he was unable to show any effect of prolactin upon the $T / S$ ratio, $\mathrm{PBI}$, or the ratios of various iodine containing components (iodide, mono-and diiodotyrosine, triodothyronine and thy. roxine) of thyroid hydrolysates of climax tadpoles, even though completion of metamorphosis was inhibited. He does shox: that PBI was reduced by prolactin in prometamorphic animals. However, since the determinations were of necessity based on pooled blood samples and not subjected to statistical comparison, the data are not completely convincing.

On the other hand Campantico et al. (1968) find that the effect of prolactin upon iodine uptake varies with the developmental stage of the tadpoles, inhibiting uptake in younger stages and stimulating in older ones. They therefore believe that prolactin stimulates the thyroid as the stage of metamorphosis approaches, and support this conclusion indirectly by showing that arginase activity, a supposedly thyroxine dependent trait, is inducer precociously in prolactin treated tadpoles (Guardabassi et al., 1970). However, even though arginase is normally induced by thyroid hormone, it does not seem to be established that this is a totally specific effect, and it is quite possible that prolactin itself; or other changes associated with prolactin treatment, are responsible for the activation of arginase. This controversy as to whether prolactin is inhibitory or stimulatory to the thyroid has becn extended to postmetamorphic newts (Grant and Cooper, 1965; Vellano et al., 1967; Gona 
et al., 1970). We are forced to conclude that the question of a central antithyroid effect of prolactin in amphibian larvae requires further investigation with careful experimental design susceptible to statistical analysis before it can be resolved one way or the other.

The evidence for a peripheral effect of prolactin in blocking metamorphosis is somewhat more convincing, though not completely without conflicting points. Bern et al. (1967) and Medda and Frieden (1970) have shown that prolactin inhibits the induction of metamorphosis caused by immersion of tadpoles in, or injection with, solutions of exogenous thyroxine. On the other hand, Gona (1967) and Brown and Frye (1969a) were not able to show any effect of prolactin in blocking metamorphosis induced by immersion of tadpoles in concentrations of thyroxine ranging, in the latter study, from $4-100 \mu \mathrm{g} /$ liter. The reasons for the difference in the results is not known, but it is possible that the antagonistic effect is achieved only at a specific balance in the concentrations of the two hormones which the latter workers were not fortunate enough to produce. It is also possible that the response to combinations of thyroid hormone and prolactin varies with the stage of development and with levels of endogenous hormones in the test animals. Ectopic pituitary grafts in tadpoles whose own pituitary is intact also retard spontaneous metamorphosis. A direct peripheral effect is indicated by the fact that the inhibition of resorption of tail tissue in the immediate vicinity of the grafts is inhibited more than in more distant areas (Etkin, Derby, and Gona, 1969). Similarly, Etkin and Derby (1968) and Derby (1970) have shown that larval pituitary grafts placed in isolated disks of tail fin in vitro prevent the resorption which is induced by thyroxine. Prolactin, and to some extent somatotropin, also prevented resorption, although the purified hormones were seemingly less effective than pituitary grafts. The relative impotency of the mammalian hormones could be due to inefficient uptake or retention of the hormone under in vitro conditions, but it could also suggest that the factor produced by the tadpole pituitary is not identical to mammalian prolactin.

\section{INTERRELATIONSHIP OF HORMONAL EFFECTS IN GROWTH AND METAMORPHOSIS}

Since prolactin both promotes larval growth and inhibits metamorphosis, the question arises whether there is a direct connection between these two effects. The level of thyroid hormone itself influences growth. Low levels enhance growth of hypophysectomized larvae (Just and Kollros, 1968), and conversely, the growth of otherwise intact tadpoles is accelerated by suppression of thyroid function (Steinmetz, 1952, 1954; Clerici and Gabanino, 1967). Thus, it is entirely possible that the growth promoting action of prolactin is entirely due to its antithyroid effects rather than to a more direct anabolic action. This possibility is enhanced by a number of additional considerations which emphasize the existence of a connection between the growth and the metamorphosis inhibiting actions of prolactin: (1) The concurrence of the growth and metamorphic effects can, of course, be most simply explained if they result from a common primary effect; (2) The magnitude of stimulation of incorporation of labeled amino acid into protein of tail muscle under the influence of prolactin is less than might be expected from the magnitude of the growth effect (Snyder, 1970). This could be explained if prolactin were antagonizing a thyroxine-dependent catabolic process rather than directly stimulating protein synthesis; and (3) Hypophysectomized larvae grow normally until about mid-larval life when growth is arresled (ef. Etkin and Lehrer, 1961). The thyroxine dependent phase of larval development begins at approximately this same time (cf. Steinmetz, 1952, 1954; Hanaoka, 1967).

The possibility that the growth effect of prolactin is solely due to its antithyroid effects has been tested by Brown and Frye (1969a) who showed that prolactin stimulates growth of tadpoles treated with propylthiouracil, or thyroidectomized, more 
than thyroid depression alone stimulates growth. In addition, Brown (1968) has shown in one experiment that in premetamorphic tadpoles (approximately stage IX of the Taylor and Kollros series; prior to the thyroxine dependent stage of metamorphosis) prolactin stimulates growth but does not affect the progression of metamorphic stages. In further support of the separateness of the growth and metamorphic effects, we have found that there is an apparent difference in the minimum dose of prolactin required to influence the two phenomena. Five micrograms per day were required to noticeably retard metamorphosis, whereas the minimum effective growth stimulating dose was between 0.5 and $1 \mu \mathrm{g} /$ day. ${ }^{1}$ These results seem to show that prolactin induced growth has two components: that caused by suppression of the production or action of thyroid hormone, and that caused by a direct anabolic effect of prolactin on the peripheral tissues. This conclusion should not be accepted too easily, however, and needs to be confirmed in at least two ways: (1) by demonstrating that the ability to produce both effects is possessed by completely pure prolactin, i.e., that the anabolic effect is not due to somatotropin contamination, for example; (2) by comparative study of the processes which are affected by prolactin, somatotropin, and thyroid hormone at the molecular level. Finally, the role of the hyroid itself in growth regulation needs to be more fully characterized. As has already been noted thyroxine stimulates net growth of hypophysectomized animals when administered at low doses, and conversely, the

\footnotetext{
${ }^{1}$ Neither of the last two arguments is of itself very strong. The first, based on the observation that young developmental stages may not be arrested in metamorphosis by prolactin is weak because the lack of an overt effect on metamorphosis as assessed by morphological criteria does not mean that effects on molecular processes common to both growth and metamorphosis are not occurring. The second, based on a higher dose requirement for metamorphosis inhibition than for growth stimulation is weak because two different endpoints used to assay the same effect may differ in sensitivity.
}

growth of otherwise intact tadpoles is accelerated by thyroidectomy and inhibited by thyroxine doses great enough to cause metamorphosis. It is thus to be expected that the response of an animal to prolactin will be variously influenced by different levels of thyroid function. The converse is equally true.

\section{GROWTH AFTER METAMORPIOSIS}

There have been very few studies of the role of the pituitary in regulating growth of postmetamorphic amphibians. Epple et al. (1966) showed that hypophysectomy accelerates loss of lean weight of fasted toads. This effect, though not measured specifically in terms of growth, presumably reflects an anabolic action of somatotropin or other pituitary hormones comparable to that seen in mammals (cf. Snipes, 1968). Subsequently, Brown and Frye (1969b) showed that hypophysectomy retards or arrests growth of juvenile frogs when measured in terms of weight or length gain. These studies suggest that the postmetismorphic amphibian pituitary may have a somatotropic function similar to that seen in mammals, but work with hormone replacement is needed to establish this. To date, such work has been restricted to the administration of purified mammalian prolactin and somatotropin. We have shown that juvenile $R$. pipiens grow in weight and lenglh in response to $5-10 \mu \mathrm{g}$ (approximately $1-2 \mu \mathrm{g} / \mathrm{g}$ ) per day but do not grow in response to doses of prolactin as high as $50 \mu \mathrm{g} /$ day over an 11 -week period. This result has been confirmed by Snyder (1970) who also showed that somatotropin stimulates incorporation of labeled amino acid into protein in muscle and gut (but not liver) whereas prolactin does not. Ripser et al. (1969) have reported similar results with two species of toads, Bufo marinus and $B$. borealis. They were able to stimulate growth in these species with as little as $0.3 \mu \mathrm{g} /$ day of somatotropin (approximately $0.1-0.03 \mu \mathrm{g} / \mathrm{g}$ ) but could obtain growth in response to prolactin only when the dose was great enough (50 $100 \mu \mathrm{g} / \mathrm{day})$ for the effect to be accounted for by contaminating somatotropin. Toads proved to 
be much more sensitive to somatotropin than frogs, both in terms of minimal effective dose and in terms of the rate of growth. Finally, Brown and Brown (1971) have recently shown that somatotropin is more effective in stimulating growth of the adult newt, Notophthalmus viridescens, than prolactin, although the difference in the response to these two hormones is not as great as in the anurans.

\section{SPECULATIONS ABOUT THE SIGNIFI- CANCE OF THE DIFFERENCES IN PRE- AND POSTMETAMORPHIC GROWTH RESPONSES}

The apparent inversion in relative sensitivity of growth processes to somatotropin and prolactin at metamorphosis requires explanation, both in terms of the mechanism of the change, and in terms of the adaptive significance of the phenomenon.

There is no information available about the mechanistic basis for the difference in sensitivity to prolactin and somatotropin before and after metamorphosis. However, several hypothetical considerations may help to focus the problem. First, on the basis of responses to mammalian hormones, we should expect to find a comparable inversion in the relative amounts of prolactin and somatotropin (or equivalent related substances) secreted by the pituitary in larval and postmetamorphic stages of development. Both prolactin and somatotropic activities are detectable in pituitaries of adult amphibians (cf. Solomon and Greep, 1959; Nicoll et al., 1966) but there is no basis for evaluating relative activity at different stages in the life cycle. Derby's work (1970) showing that metamorphosis inhibiting activity of larval pituitaries declines during metamorphosis to become undetectable in the juvenile frog is suggestive of a decline in prolactin, but needs to be confirmed by the use of standard prolactin and somatotropin assays. Second, changes in the sensilivily to prolactin and growth hormone during development could reflect changes in the activity of other synergistic or antagonistic hormones rather than fundamental changes in the response to prolactin or somatotropin at the molecular level. The possible complex interactions of the thyroid and pituitary hormones in larval growth have already been mentioned and may extend to postmetamorphic development. Third, the fundamental molecular basis of the response to prolactin and somatotropin must be known before the meaning of changes in sensitivity based on overt growth can be evaluated. If prolactin and somatotropin promote growth in totally different ways, for example, if prolactin inhibits catabolic processes and somatotropin stimulates anabolic processes, then differences in the kinetics of larval and subadult enzymes controlling each of these processes could lead to apparent metamorphic changes in the sensitivities of the processes to the hormones controlling them even though the primary molecular responses to the hormones had not, been altered. On the other hand, if both hormones promote growth through the same anabolic pathways, then differences in sensitivity at different stages of development imply changes in the primary events of hormone action. Finally, it is possible that prolactin and somatotropin are acting upon different cells or tissues which comprise different proportions of the organism before and after metamorphosis. In this case, changing pallerus of response to prolactin and somatotropin would not involve cellular differentiation per se, but would reflect a decline in the numbers of prolactin sensitive cells, and a rise in numbers of growth hormone sensitive cells comprising the hormone sensitive tissues.

Perhaps the most intriguing and difficult question which arises from the work which has been described is that of the adaptive significance of the metamorphic transition from prolactin to somatotropin control of growth. Assuming that the implication of the work with mammalian hormones is correct-namely that the ability to secrete and respond to both prolactin and somatotropin is within the genetic capabilities of an amphibian-what considerations have favored the use of prolactin during the larval phase of growth and somatotropin during postmetamorphic growth? Studies of the molecular basis of the effects 
of the two hormones, by revealing exactly what each is doing, may provide some insight into this question. But the total picture can become apparent only by consideration of the complete spectrum of effects of each of the hormones and the relationships of these effects to growth on the one hand and to special features of larval or postmetamorphic life on the other. For example, it is well known that the growth promoting effects of somatotropin in mammals are accompanied by numerous interrelated effects upon the metabolism of carbohydrate, fat and protein, which are conducive to the shunting of as much of the available foodstuffs as possible into lean growth while simultaneously sustaining carbohydrate reserves necessary for other metabolic requirements. It seems apparent that a growth-regulating hormone with these complementary effects would, in the course of evolution, have selective advantage over a hormone ${ }^{2}$ with effects less encompassing of the relevant features of the biology of the organism. Thus, it is of inlerest to know whether there are aspects of the composite actions of prolactin and somatotropin which could enhance their value as growth regulators in the larval and the postmetamorphic stages of development, respectively. There appear to be only two relevant sets of observations bearing on this problem: (1) As already discussed, prolactin both inhibits metamorphosis and stimulates growth during the larval phase of development. It seems apparent that prolactin, by combining these two properties, has superiority over somatotropin as a mechanism for fully exploiting the larval phase of development, and (2) The effects of somatotropin and prolactin upon the composition of the body with respect to major foodstuffs appear to be different in the two stages of development. In the larval stage neither prolactin nor somatotropin have any major effects on the relative content of

\footnotetext{
${ }^{2}$ Obviously the hormone as a chemical entity of itself has no adaptive or evolutionary significance outside of the context of the target which it affects, and we are in reality speaking here of the hormone-target system.
}

any major biochemical constituent. But in the juvenile frog (Snyder and Frye, 1971) or toad (Zipser et al., 1969) somatotropin, in additon to stimulating protein synthesis and growth, causes a pronounced reduction in lipid and glycogen stores. Conversely, hypophysectomy elevates lipid and glycogen content relative to controls (Snyder and Frye, 1971; Epple et al., 1966). Prolactin has much less effect on biochemical composition, although it tends to cause changes in the same direction as somatotropin when it has any effect at all. Thus, as in mammals, somatotropin has interrelated effects in the juvenile anuran which tend to shunt a large portion of the caloric intake or reserve into growth rather than energy storage depots. ${ }^{3}$ It is possible that such effects on the metabolic balance in the use of foodstuffs would be of no value in the continuous feeding, herbivorous tadpole, or even unadaptive by virtue of antagonizing the storage of energy reserves which are needed in metamorphosis. The full arguments behind these ideas are too complex and lengthy to present here, and the reader is asked to consult Snyder and Frye (1971) for further details.

\section{REFERENCES}

Allen, B. M. (1929). Quart. Rev. Biol. 4, 325-372.

Berman, R. H., Bern, H. A., Nicoll, C. S., and StrohmaN, R. C. (1964). J. Exp. Zool. 158, $353-360$.

Bern, H. A., Nicoly, C. S., and Strohman, R. C. (1967). Proc. Soc. Exp. Biol. Med. 126, 518-520.

BerN, H. A., ANd Nicoll, C. S. (1968). Recent Prog. Horm. Res. 24, 681-720.

Br.ATt, T. M, Sitckers, K. A., ANm Kiy, F. B. (1969). Endocrinology 85, 1213-1215.

Bounhiol, J. J., Disclos, G., and Drsclos, P. (1959). Assne. Anat. XLVI Reunion, 118-123.

Brown, P. (1968). PhD Dissertation, Zoology, University of Michigan. $134 \mathrm{pp}$.

${ }^{3}$ The glycogenolytic effect of somatotropin in frogs is, of course, the opposite of the effect of this hormone in mammals, where it causes glycostasis. The glycostatic effect of the hormone in mammals is apparently related to special metrbolic requirements for glucose which do not seem to hold true for amphibians and may, in fact, favor the glycogenolytic role of somatotropin (cf. Snyder and Frye, 1971). 
Brown, P., and Frye, B. E. (1969a). Gen. Comp. Enducinol. 13, 126-138.

Brown, P., and Frye, B. E. (1969b). Gen. Comp. Endocrinol. 13, 139-145.

Brown, P., and Brown, S. (1971). J. Exp. Zool. (In press).

Campantico, E., Oxivero, M., and Peyrot, A. (1968). Ric. Sci. 38, 980-985.

Cherict, P., and Gabanino, E. (1967). Monit. Zool. Ital. 1, 91-99.

Derbe, A. (1970). J. E'xp. Zool. 173, 319-328.

Derby, A., and EtKin, W. (1968). J. Exp. Zool. $169,1-8$.

Enemar, A., Essvik, B., and Klang, R. (1968). Gen. Comp. Endocrinol. 11, 328-331.

Enemar, A., and Mechlentbura, C. (1962). Gen. Comp. Endocrinol. 2, 273-278.

Epple, A., Jorgensen, C. B., and Rosenkitde, P. (1966). Gen. Comp. Endocrinol. 7, 197-202.

Erkin, W. (1968). In "Metamorphosis," (W. Etkin and L. Gilbert, eds.). Appleton-CenturyCrofts, New York. Pp. 313-348.

Etkin, W., Derby, A., and Gona, A. (1969). Gen. Comp. Endocrinol. Suppl. 2, 253-259.

Erkin, W., And Gona, A. (1967). J. Exp. Zool. $165,249-258$.

Etkin, W., AND Lehrer, R. (1960). Endocrinology 67, $457-466$.

Frieden, E. (1968). In "Metamorphosis," (W. Etkin and L. Gilbert, eds.). Appleton-CenturyCrofts, New York. pp. 349-398.

GoNA, A. (1967). Endocrinology 81, 748-754.

Gona, A. (1968). Gen. Comp. Endocrinol. 11, 278-283.

Gona, A., and Etkin, W. (1970). Gen. Comp. Endocrinol. 14, 589-591.

Gona, A., Peariman, T., and Etrin, W. (1970). J. Endocrinol. 48, 585-590.

Grant, W. C. JR., and Cooper, G. (1965). Biol. Bull. 129, 510-522.
Guardabassi, A. (1961). Gen. Comp. Endocrinol. 1, 348-363.

Guardabassi, A., Olfiero, M., Campantico, E., Rinaudo, M. T., Giunta, C., and Bruno, R. (1970). Gen. Comp. Endocrinol. 14, 148-151.

HaNaOKa, Y. (1967). Gen. Comp. Endocrinol. 8, $417-431$.

Just, J. J., and Kollios, J. J. (1968). Am. Zool. $8,762$.

Mrdda, A. K., and Frieden, E. (1970). Endocrinology $87,356-365$.

Medda, A. K., ANd Frieden, E. (1972). Gen. Comp. Endocrinol. (In press.)

MeIer, A. (1969). Gen. Comp. Endocrinol. Suppl. 2, 55-62.

Nicold, C. S., Bern, H., Dunlop, D., and StrohMaN, R. (1965). Amer. Zool. 5, 739.

Olivero, M., Latthis, M. G., Campantico, E., and Toppino, G. (1967). Ric. Sci. 37, 997-1004.

Rémy, C., and Bounhiol, J. J. (1965). Compt. R. Soc. Biol. 159, 1532-1535.

Rémy, C., and Bounhiol, J. J. (1966). Ann. Endocrinol. 27, 377-382.

Smitr, P. E. (1920). Amer. Anat. Mem. No. 11.

SNyper, B. W. (1970). PhD. Dissertation, Zoology, University of Michigan. $95 \mathrm{pp}$.

SNyder, B. W., and Frye, B. E. (1971). J. Exp. Zool. (In press.)

Steinmetz, C. H. (1952). Endocrinology 51, 154-156.

Stennmetz, C. H. (1954). Physiol. Zool. 27, 28-40.

Vellano, C., Pexrot, A., and Mazzi, V. (1967). Monit. Zool. Ital. 1, 207-227.

WILLIER, B. H. (1955). In "Analysis of Development," (B. H. Willier, P. A. Weiss, and V. Hamburger, eds.), W. B. Saunders, New York. Pp. $574-619$.

Yoshizato, K., and Yasumasu, I. (1970). Develop. Growth, \& Differentiation 11, 305-317.

\section{DISCUSSION}

BAGNARA: In consideration of growth in larvae one seldom considers the intrinsic growth rate of tadpoles. Hypophysectomized tadpoles continue to grow long after their siblings have metamorphosed. Some become as much as twice as large as their siblings when metamorphosed. There also seems to be differential growth with soft tissues growing more than skeletal elements.

FrYe: One implication of Dr. Bagnara's comment is that there may be differential responses of different tissues to hormones which stimulate growth. As stated in the text, there have been very few studies of this, although it is quite clear that the growth of the tail or tail fin responds more intensely to prolactin than other tissues.

HANKE: In regard to the comment by Dr. Bagnara, hypophysectomized tadpoles of Xenopus have large fat bodies. After treatment of these larvae with ACTH or corticosteroids the fat body size and the amount of triglycerides in the body are reduced (Guneseh, our laboratory).

Bagnara: What growth criteria do you use in larvae and adults? I think that 
water uptake may be an important phenomenon in comparing growth effects in larvae and adults. This is especially important in view of the implications of prolactin in water balance.

Frye: Water uptake may be an important factor, especially in view of the weil known osmoregulatory effects of prolactin in fish. However, the criteria used inm clude, in addition to wet weight, increases in linear dimensions, dry weight, and: incorporation of C-14 labeled amino acids into protein. All of these criteria seem to indicate that we are dealing with real growth and not merely water uptake.

Lichr: In regard to the comment by Dr. Bagnara, criteria for growth in tadpoles are extremely important and may account for apparent discrepancies. For example, in Rana catesbeiana, STH stimulates trunk growth but not tail growth, whereas prolactin has the reverse effect. Failure to measure trunk length accounts for the earlier conclusion that STH is not somatropic in this tadpole.

PESeTSKr: If I understood you correctly, Dr. Frye, you reported that your thyroidectomized tadpoles grew at a rate gxeater than that of normal larvae. This contrasts with my experience with Rana pipiens tadpoles thyroidectomized in embryonic stages. Although these larvae, in a year or so, grew to "giant" size, their rate of growth seemed no greater than that of young normal larvae, and, indeed, the rate of growth may be a bit slower than normal.

Frye: In our work as well as some others, growth rate of tadpoles thyroidec. tomized in midlarval development (Taylor-Kollos Stage XII-XV) was accelerated relative to controls. However, this is very probably due to the fact that during the experimental period the controls reached the growth plateau which precedes overt metamorphosis rather than to a positive acceleration of the growth of thyroidectomized animals. You are correst, in pointing out this distinction.

Pesersky: You have demonstrated that in larvae, thyroidectomy results in an increase in sensitivity to STH. Would you care to speculate on the possibility that the "inversion" of response to STH after metamorphosis might be a result in the postmetamolphic drop in thyroid activity. Thus, the adult, like the thyroidectomized larvae, would display a heightened response to growth homone.

FrYe: This is a possibility that has occurred to us but has not yet becn tested. However, by analogy with mammals one would expect some thyroxin to be required to synergize with somatotropin to get the maximum growth response to the latter hormone.

LICHT: Regarding Dr. Pesetsky's comment, administration of TSH to postmetam morphic toads does not influence the activity of exogenous STH.

LICIIT: Conclusions regarding the relative importance of STH versus prolactin on growth of postmetamcrphic Anura must be made eautiously. Dr. Nicoll and I have recentiy found that STH from all tetrapods stimulates growth in the toad (Bujo bureas), and many prolactins do not. However, some prolactins (e.g., from ovine, bovine, turtle, and possibly toad) are also highly potent somatotropins in the postmetamorphic toad.

Kaltrinach: Prolaetin is known to stimulate the water drive in the red eft. Does it also stimulate growth in this animal?

BRown: Waterman (1965) has reported increase in body weight in red efts in response to prolactin. We have also found that both prolactin and $\mathrm{GH}$ increase growth rate in aquatic adult-stage Notopthalmus viridescens, with GH being more effective.

KALTENBACH: Does prolactin have any effect on gonad development of the tadpole?

$F_{R Y E}$ I do not know; no one appears to have examined this question. You may be alluding to recent reports that prolactin has gonad inbibiting activity in the European newt (4). It would be of interest to know if prolactin plays any role in delaying gonad maturation of larvae until after metamorphosis.

NicotL: Unfortunately, we did not measure trunk length in the tadpoles which we treated with prolactin and growth hormone. We only measured the tail and body weight. However, we are beginning to think that many of the reported 
somatotropic effects of ovine prolactin among the vertebrates may be only of academic interest and have no real physiological significance. Preparations of ovine prolactin are claimed to have somatotropic effects in animals ranging from teleosts to mammals, including man. In the latter species, ovine and bovine growth hormones are inactive. In sheep, ovine prolactin does not act like growth hormone. Another example of a target organ that fails to discriminate among prolactins and somatotropins is the mouse mammary gland, which shows a lactogenic response to ovine or bovine growth hormone. These examples illustrate that with heterologous hormones, the receptors for prolactin and growth hormone are frequently poor discriminators. This serves to emphasize the importance of using homologous hormones for obtaining meaningful physiological information.

GESCHWIND: In the hypophysectomized mammal, growth hormone synergizes with small amounts of thyroxine in producing growth. Does such a synergism occur in the hypophysectonized adult amphibian?

FRYE: So far as I am aware there have been no studies of the role of the thyroid in the growth of post-metamorphic amphibians, so we do not know whether synergism between growth hormone and thyroxine occurs as in mammals. In larval amphibians the situation is complex. For example, thyroidectomy has been reported to increase growth of animals with intact pituitaries, whereas the growth of hypophysectomized tadpoles can be restored to normal by very small doses of thyroxin without any pituitary hormones present.

HANKe: ACTH and corticosteroids are also involved in the induction of metamorphic changes. One of my coworkers, Dr. Leist, could demonstrate that ACTH or corticosteroids support the metabolism on a metabolic basis. These hormones accelerate metamorphosis in accelerating metabolic changes which occur during development. 